\title{
LOGISTICA REVERSA: UMA ESTRATÉGIA EMPRESARIAL NA COLETA DE EMBALAGENS VAZIAS DE AGROTÓXICOS
}

\author{
Juliano DALEASTE \\ Rodrigo FRANCISCO ${ }^{2}$
}

César Augustus WINCK ${ }^{3}$

Recebido em: 25/10/2015 - Aprovado em: 17/04/2016 - Disponibilizado em: 30/07/2016

\begin{abstract}
RESUMO
Em um mundo globalizado, onde a sustentabilidade está se tornando sinônimo de competitividade, manter-se no mercado é um desafio encarado por pequenas e grandes empresas, e adotar a logística reversa como parte de seus processos de destinação final de resíduos e bens inservíveis é uma estratégia que está dando resultados positivos. Evitar a degradação do meio ambiente com a disposição de lixo de forma inadequada é uma questão de prioridade ate mesmo para o governo que tem oferecido benefícios para empresas que assim procederem. O objetivo desse artigo é apresentar um plano de trabalho sustentável no que diz respeito á destinação correta das embalagens vazias de agrotóxicos em uma propriedade rural do Oeste de Santa Catarina, visando à redução dos impactos ambientais causados pela destinação incorreta de resíduos contaminados no meio ambiente. É uma região onde o agronegócio é predominante e tem-se a necessidade de destinar corretamente as embalagens vazias dos produtos utilizados nas atividades, de modo que a sociedade e o meio ambiente fiquem seguros em relação aos riscos por eles oferecidos. $\mathrm{O}$ artigo compreende uma abordagem descritiva e exploratória, quantitativa e seguida de um estudo de caso desenvolvido através de um levantamento de dados a respeito da quantidade de embalagens vazias de agrotóxicos. A partir do estudo, conclui-se que, além da obrigatoriedade, a busca por se tornar ecologicamente correto é o principal fator motivacional para a implantação da reciclagem de embalagens de agrotóxicos, o que possibilita, entre tantos outros fatores, a preservação do meio ambiente.
\end{abstract}

Palavras-chave: Sustentabilidade, Logística Reversa, Embalagens de Agrotóxicos.

\begin{abstract}
In a globalized world, where sustainability is becoming synonymous with competitiveness, remain in the market is a challenge faced by small and large businesses, and adopt reverse logistics as part of its disposal of process waste and scrap goods is a strategy that is yielding positive results. Prevent degradation of the environment with the disposal of garbage inappropriately it is a matter of priority up to the same government that has offered benefits to companies who do this. The aim of this paper is to present a sustainable work plan in what concerns the proper disposal of empty containers of pesticides on a farm the West of Santa Catarina, in order to reduce the environmental impacts caused by improper disposal of contaminated waste in the environment. It is a region where agribusiness is prevalent and there is the need to properly allocate empty containers of the products used in the activities, so that society and the environment are secure against the risks they offered. The article comprises a descriptive and exploratory approach, quantitative and followed by a case study developed through a survey of data on the amount of empty pesticide containers. From the study, it is concluded that in addition the obligation, the quest to become environmentally friendly is the main motivational factor for the implementation of recycling of pesticide containers, which allows, among many other factors, the preservation of the environment.
\end{abstract}

Keywords: Sustainability, Reverse Logistics, Pesticide Packaging.

\footnotetext{
${ }^{1}$ Graduado em Ciências Econômicas. Especialista em Gestão da Produção e Logística. MBA em finanças. Mestrando em Administração (UNOESC Chapecó), Email: daleaste@ hotmail.com

${ }^{2}$ Graduado em Administração. Mestrando em Administração (UNOESC Chapecó), Email: rodrigofrancisco85@hotmail.com

${ }^{3}$ Doutor em Agronegócios. Cadeias competitivas do agronegócio. Prof ${ }^{\mathrm{o}}$ Doutor do Mestrado Profissional em Administração (UNOESC Chapecó). Email: cesar.winck@ unoesc.edu.br 


\section{INTRODUÇÃO}

Em meio á concorrência notória do mercado, manter-se competitivo está sendo o foco de toda a organização, independente do seu ramo de atividade. A logística que outrora era vista apenas como um apoio na aquisição, recepção e expedição de produtos de consumo ou matéria prima industrial, hoje está sendo encarada como uma estratégia para as empresas, quando se trata de produtos de curto ciclo de vida ou então aqueles que possuem embalagens que se depositadas no meio ambiente de forma incorreta, podem causar grandes impactos, muitas vezes irreversíveis, perdendo seu conceito de sustentabilidade perante seus concorrentes.

A logística reversa pode ser entendida como um processo complementar à logística tradicional, pois enquanto a última tem o papel de levar produtos dos fornecedores até os clientes intermediários ou finais, a logística reversa deve completar o ciclo, trazendo de volta os produtos já utilizados dos diferentes pontos de consumo a sua origem (LACERDA, 2008, P.8).

Por sua vez, a logística reversa, está sendo utilizada como uma estratégia pelas empresas, permitindo que o resíduo gerado ou um bem inservível, retorne ao seu fornecedor para quo o mesmo providencie a destinação correta, reciclando o que ainda pode ser reaproveitado conforme prevê a legislação ambiental vigente. Além, de reduzir os custos com a destinação destes resíduos, a prática da logística reversa tem incentivado os fabricantes a repensarem melhor sobre os recursos utilizados para a produção de um determinado produto, para que no momento de seu descarte, ele possa causar o menor impacto possível.

Por ser um problema para o meio ambiente, a destinação correta de embalagens vazias de agrotóxicos é uma preocupação que tem feito as empresas e fornecedores a repensarem-nas variadas formas de evitar que este resíduo seja depositado no meio ambiente de forma incorreta. A propriedade rural em estudo faz uso de agrotóxicos e a necessidade de dar uma destinação ambientalmente correta para as embalagens vazias é o desafio enfrentado constantemente. Dessa forma, qual é a maneira correta de destinação destas embalagens? Qual a melhor estratégia a ser utilizada?

Iniciou-se o estudo através de um levantamento de dados sobre a destinação correta das embalagens vazias de agrotóxicos no que diz respeito à quantidade mensal gerada, o custo que sua destinação pode trazer para os produtores rurais, bem como a forma de armazenamento utilizada antes de sua destinação. Posteriormente, foi verificado a forma de destinação das embalagens, identificando os reais impactos que a destinação incorreta pode causar ao meio ambiente. 
Para finalizar o estudo, foram apresentados os resultados obtidos através dos dados levantados, informando se os processos atuais de armazenamento e destinação final atendem a Legislação Ambiental vigente apontando as principais vantagens $\mathrm{e}$ desvantagens da aplicação da Logística Reversa na destinação correta destas embalagens.

\section{FUNDAMENTAÇÃO TEÓRICA}

\subsection{SUSTENTABILIDADE}

A preocupação com os problemas ambientais tem se intensificando ano após ano, demonstrando ser cada vez mais urgente e necessária uma mudança de comportamento em relação ao meio ambiente para que não se degrade ainda mais. Este debate já tem sido abordado há muito tempo. $\mathrm{O}$ primeiro grande evento foi a Conferência de Estocolmo, realizada em 1972 na Suécia. Em 1980 a Organização Internacional para a Conservação do Ambiente patrocinou estudos acerca da conservação dos recursos naturais, buscando o desenvolvimento sustentável (DS). A extraordinária expansão da conscientização sobre o desenvolvimento sustentável levou à realização da Eco-92, no Rio de Janeiro.

Grande parte dos estudos científicos destaca que a sustentabilidade é composta de três dimensões que se relacionam: econômica, ambiental e social, que são conhecidas como tripple bottom line. A dimensão econômica inclui não só a economia formal, mas as atividades informais que proveem serviços para os indivíduos e grupos e aumentam a renda e o padrão de vida dos indivíduos (ALMEIDA, 2002). A dimensão ambiental estimula empresas a considerarem o impacto de suas atividades sobre o meio ambiente por meio da utilização dos recursos naturais, buscando o gerenciamento da sustentabilidade ambiental na rotina de trabalho (SAVITZ, 2007). A dimensão social consiste no aspecto social relacionado às qualidades dos seres humanos, como suas habilidades, dedicação e experiências, abrangendo tanto o ambiente interno da empresa quanto o externo (ALMEIDA, 2002).

Compreender a sustentabilidade a partir da articulação entre as diferentes dimensões, sem a primazia de uma sobre a outra. Aspectos econômicos, quando se pensa em iniciativas empreendidas em busca de geração de trabalho e renda, são fundamentais à consolidação dos empreendimentos; todavia, o social e o político também terão influências significativas na gestão e na sustentabilidade (Reis, 2005).

É crescente o interesse sobre sustentabilidade (ou DS). Veiga (2010) destaca que a sustentabilidade não pode ser entendida como conceito, mas como um valor, e devido a uma evolução que ainda 
demanda tempo para ser bem entendida, o termo sustentabilidade passou a servir a todos quando querem exprimir vagas ambições de continuidade, durabilidade e perenidade.

Duas definições de sustentabilidade conhecidas são enfaticamente rejeitadas por Philippi (2011) destacando que sustentabilidade não se trata de "alcançar as necessidades do presente, sem comprometer a capacidade das futuras gerações de alcançar suas próprias necessidades", conforme apresenta o Relatório Bruntland. O tema não pode ser resolvido pelo tripé, em que econômico, social e ambiental são analiticamente separados para posteriormente se juntarem de forma triangular. Salienta que mesmo neste sentido fica de fora o essencial, isto é, a identificação de que "a sustentabilidade é um valor e, portanto, um convite para que se desfaça o mais importante pilar das ciências sociais de nosso tempo, o que afastou a economia da ética e a sociedade da natureza." (VEIGA, 2010). Em relação à definição do Relatório Bruntland, Veiga (2010) diz que não é possível falar genericamente de necessidades, presentes ou futuras, sem que se discutam os padrões de consumo contemporâneos.

Em relação ao tripple bottom line, Veiga (2010) diz que a sustentabilidade não consiste em fazer mais do mesmo, porém ter menos danos ambientais e uma preocupação maior com o social. É o mais importante para as sociedades contemporâneas cujo objetivo básico é a organização das políticas e dos agentes econômicos em relação ao crescimento da produção de bens e serviços que são analisados pelo PIB (Produto Interno Bruto).

Moura (2011) menciona que estudar a sustentabilidade como um valor não retira em nada o alcance científico do uso desse termo e que por mais que o progresso técnico e a mobilização social tenham contribuído para reduzir a insustentabilidade de alguns dos mais importantes processos produtivos atuais, sabe-se que o consumo de materiais, de energia e as emissões de gases de efeito estufa não cessam de aumentar. Ainda segundo o autor, os ganhos de eficiência foram globalmente mais que contrabalançados pela elevação espetacular do consumo e que mesmo que não seja possível definir claramente a sustentabilidade, é possível dizer que a trajetória atual das sociedades humanas é insustentável.

Muito do debate sobre o Desenvolvimento Sustentável, Sachs (2004) diz que fica concentrado em um discurso vazio, olhando apenas os aspectos econômicos. O que é dito não é revertido em ações que tragam melhorias socioambientais direcionadas à sustentabilidade. Segundo Sachs (2002) existe oito dimensões da sustentabilidade que devem ser levadas em conta: 1) Social, 2) Cultural, 3) Ecológica, 4) Ambiental, 5) Territorial, 6) Econômica, 
7) Política - Nacional, 8) Política Internacional:

As dimensões de Sachs (2002) sobre desenvolvimento apresentam uma nova proposta, como uma estratégia alternativa à ordem econômica internacional, enfatizando a importância de modelos locais baseados em tecnologias apropriadas, em particular para as zonas rurais, buscando reduzir à dependência técnica e cultural e que para alcançarmos a sustentabilidade, se faz necessário a valorização das pessoas, de seus costumes e saberes. Fica evidente para Sachs (2002) que se deve ter uma visão holística dos problemas da sociedade, para além do foco apenas na gestão dos recursos naturais com um pensamento mais profundo, que busca uma verdadeira transformação do modelo civilizatório atual.

Elkington (2001) em sua obra, Canibais com Garfo e Faca, apresentou tendências em relação às linhas dos três pilares (triple bottom line) e propostas de avaliação, indicadores, auditoria, relatórios e benchmarking. Destacou que os três pilares da sustentabilidade econômica, social e ambiental foram mencionados inicialmente no relatório "Our Commom Future" ("Nosso Futuro Comum"), em 1987. Também, que o conciliamento da agenda da sustentabilidade, proposta como uma tentativa de harmonizar os fundamentos financeiros tradicionais com o pensamento emergente sobre os fundamentos ambientais está se revelando muito mais complicada do que alguns empresários entusiastas precocemente imaginaram.

Para Elkington (2001) cada vez que se pensa em termos de um "resultado final tríplice", focando em prosperidade econômica, qualidade ambiental, tende-se que os negócios desconsiderem - justiça social. Em relação à transição da sustentabilidade é necessário que se pare de dar ênfase no crescimento (com foco na quantidade) para desenvolvimento sustentável (com foco nas qualidades econômicas, ambientais e sociais).

Entre outros modelos que se baseiam no triple bottom line, como o desenvolvido por Hart e Milstein (2003) defende a ideia de que as empresas que investem em sustentabilidade de forma estratégica podem adicionar valor compartilhado, não só para os donos ou acionistas, mas também para uma ampla gama de stakeholders, como funcionários, fornecedores, comunidade do entorno, meio ambiente e, em última instância, a sociedade como um todo. Hart e Milstein (2003) afirmam que os desafios globais associados à sustentabilidade, considerados sob a ótica dos negócios, podem ajudar a identificar estratégias e práticas que contribuam para um mundo mais sustentável e, simultaneamente, que sejam direcionadas a gerar valor para o acionista. Os autores desenvolvem as justificativas para criação de valor compartilhado usando uma matriz cujos eixos representam o tempo 
(curto e longo prazos) e o ambiente (interno e externo).

Em relação à agenda emergente da sustentabilidade Elkington (2001) acredita ser necessário que se pense em décadas, gerações e até mesmo séculos à frente, enquanto os líderes empresariais e políticos acham difícil pensar três anos à frente. Acredita sermos capazes de alcançar a sustentabilidade de longo prazo e que esta dependerá da habilidade da sociedade em ajudar a acionar capitalistas, mercados financeiros, empreendedores, classes dirigentes e consumidores das economias emergentes, das nações em desenvolvimento e dos países menos desenvolvidos.

Argumenta Elkington (2001) que os negócios serão feitos em mercados muito mais abertos à concorrência e que a sustentabilidade se tornará uma condutora nesse novo ambiente operacional, que os negócios não serão utilizados pela concorrência como desculpa para não aceitar a agenda do tripé para um novo enfoque como parte dos negócios para ação e investimento. Haverá uma transição de valores comerciais "duros" para valores "mais flexíveis" do tripé de valores fundamentais, que será básico para a transição para a sustentabilidade. Esses novos sistemas de valor incluirão mais questionamentos de autoridades e a junção de novas tecnologias para divulgar e analisar as informações. (ELKINGTON, 2001).
Elkington (2001) salienta também que tudo ficará resumido a um mundo cor de rosa e que provocará três tipos de resposta corporativa: a camuflagem, isto é, operando fora do radar da sociedade; uso das novas informações como inteligência competitiva para defender interesses entrincheirados; e integração das considerações do resultado final tríplice nas estratégias empresariais. As empresas estão sendo questionadas sobre suas atividades não apenas no ponto de venda, terão que se expor a uma nova forma de 'radiografia ambiental', em que suas cadeias de valor e ciclos de vida de produtos serão expostas a escrutínio mais amplo. Destaca que novas formas de parcerias vão se desenvolver entre empresas e outras organizações, e que a tecnologia e a administração "just in time" demonstram que as empresas estão sendo submetidas a pensarem em prazos muito curtos, enquanto a agenda de sustentabilidade é "de longo prazo", o que tem provocado tensão fundamental para o compromisso com a sustentabilidade.

\subsection{LOGÍSTICA REVERSA}

Para Gonçalves-Dias e Teodósio (2006), a abordagem de fluxos e canais reversos se evidenciou na literatura a partir de 1970, e o conceito de cadeia de suprimentos reversa ainda está em construção, com crescente interesse por parte de acadêmicos e gestores de empresas. 
Entre as diversas definiçõos de logística reversa, uma das que têm sido mais utilizadas na literatura é a apresentada pelo Grupo de Trabalho Europeu em Logística Reversa (RUBIO, CHAMORRO, MIRANDA, 2008), que a define como um processo de planejar, implementar e controlar fluxos reversos de matéria-prima, em processos de estocagem, embalagem e produtos finais, das fases de produção, distribuição e consumo para sua recuperação ou disposição apropriada. Assim, a Logística Reversa implica que o enfoque restrito de encontrar as alternativas mais eficientes para levar os produtos aos consumidores seja substituído por um fluxo que assegure a destinação segura, privilegiando a reinserção do material no processo produtivo da própria empresa ou a comercialização em mercados secundários. A Figura 1 demonstra o ciclo da Logística Reversa.

Figura 1. Esquematização da Logística Reversa

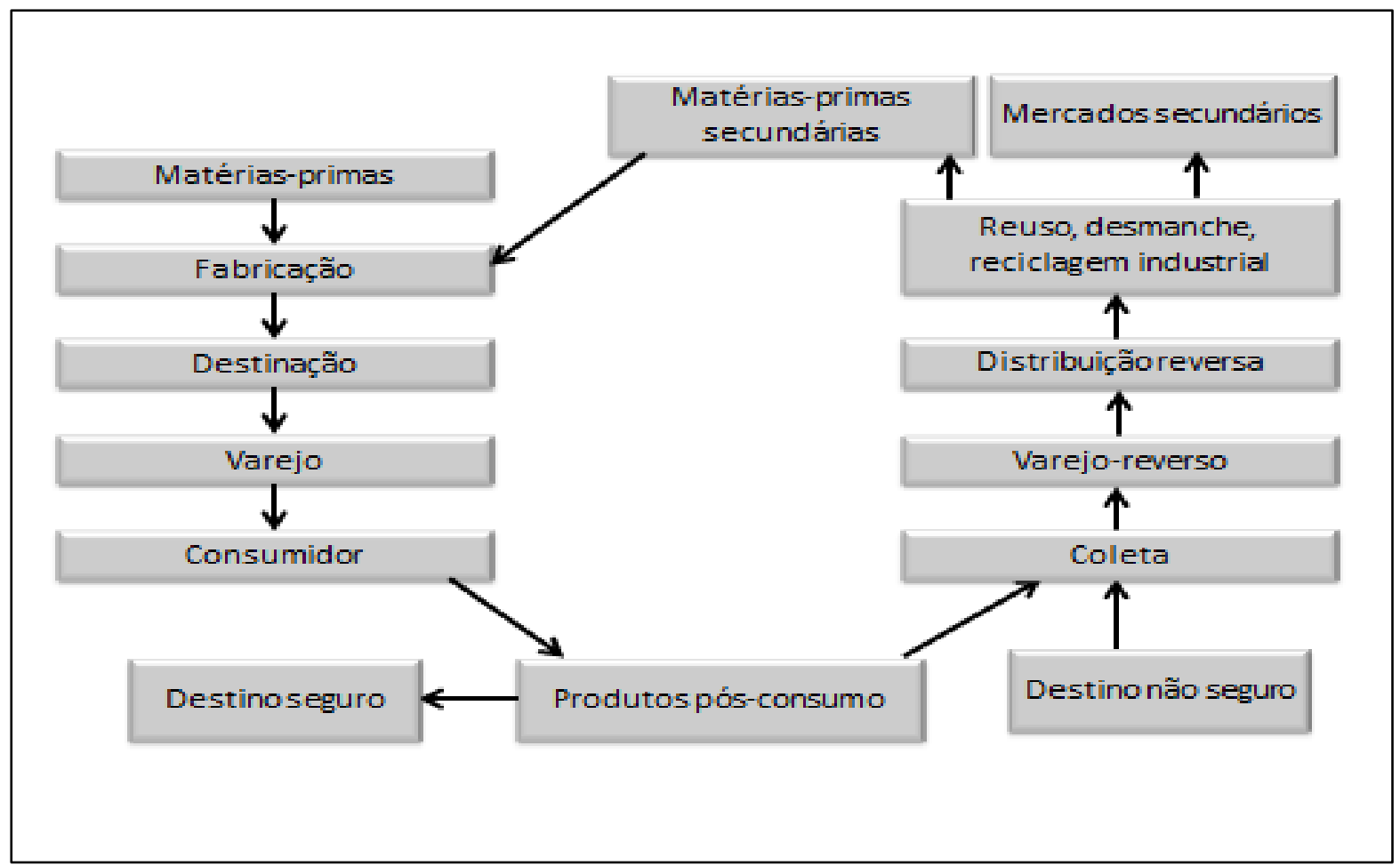

Fonte: Mueller, 2005.

As empresas, cada vez mais, são pressionadas a lidar com a devolução/retorno de seus produtos, obrigadas por regulamentações ambientais e pelos custos crescentes com o descarte de produtos (PRAHINSKI e KOCABASOGLU, 2006).
Para o Zucatto, Welle e Silva (2013), os motivos pelos quais as empresas desenvolvem e implementam estratégias de logística reversa (estruturando cadeias de suprimentos reversas) são diversos e entre os principais, se destacam: 
Leis ambientais que forçam as empresas a recolherem seus produtos e cuidar da manutenção e tratamento;

$\checkmark$ Benefícios econômicos de usar produtos devolvidos no processo de produção em vez de pagar pelos altos custos de eliminação;

A crescente consciência ambiental dos consumidores.

Tibben-Lembke (2002) complementa que existem algumas razões estratégicas para o desenvolvimento da logística reversa:

$\checkmark$ Razões competitivas - diferenciação por serviço;

$\checkmark$ Limpeza dos canais de distribuição;

$\checkmark$ Proteção das margens de lucro;

$\checkmark$ Recaptura de valor e recuperação de ativos.

No que diz respeito às crescentes restrições que os marcos regulatórios exercem sobre as atividades produtivas, pode-se exemplificar no Brasil a Lei n. 9.974, de 2000, que estabelece as diretrizes sobre a gestão de embalagens de defensivos agrícolas, e a Lei n. 12.305, que institui a Política Nacional de Resíduos Sólidos (BRASIL, 2010).

Para Guide Junior, Harrison e Van Wassenhove (2003), na recaptura de valor, cada tipo de retorno demanda uma cadeia de suprimentos reversa, adequada às características dos produtos que retornam para otimizá-la.
Segundo Bowersox, Closs e Helferich (1986), a logística reversa não tem o intuito de melhorar a produtividade logística. No entanto, a logística reversa é justificada sobre um contexto social e deve ser acomodado no planejamento do sistema logístico. Outra questão importante é que a estratégia logística da companhia não poderá ser formulada sem levar em consideração as necessidades da logística reversa.

A logística reversa torna possível o retorno de bens ou de materiais ao ciclo produtivo, agregando valor econômico, legal e ecológico (LEITE, 2003). Os objetivos principais dessa lógica são os de recapturar valor e oferecer uma disposição final adequada (NOVAES, 2007).

Em uma sociedade cada vez mais consciente da relação entre ações empresariais e impactos ambientais, práticas como a da Logística Reversa melhorariam a imagem das organizações, impactando na participação de mercado. Por fim, as pressões competitivas viriam da necessidade das empresas de reduzir custos. Por tanto, a implantação de um sistema de Logística Reversa, quando acompanhada de inovação em produtos e processos, pode gerar novas fontes de receita, compensando, muitas vezes, o custo com o investimento inicial feito.

Os aspectos estruturantes das cadeias de suprimento reversas, de acordo com Leite (2006), podem ser de: 
$\checkmark$ Natureza econômica, quando objetivam resultados financeiros $\mathrm{e}$ lucro;

$\checkmark$ Serviço ao cliente, quando procuram oferecer diferenciais da empresa nos serviços prestados;

$\checkmark$ Institucionais, quando visam à observação dos marcos regulatórios pertinentes;

$\checkmark$ Cidadania corporativa, quando o objetivo é de atender a demandas de stakeholders, e visam legitimar, reforçar ou proteger a imagem corporativa ou da marca.

De Brito e Dekker (2002) consideram importante a análise das características do produto que será descartado ou retornado, listam três características importantes: composição da embalagem, padrão de uso e características de deterioração.

$\checkmark$ Composição da embalagem: diz respeito às características intrínsecas à embalagem e são determinadas durante a fase de design: facilidade de desmontagem, homogeneidade dos elementos constituintes, presença de materiais perigosos e facilidade de transporte;

$\checkmark$ Padrão de uso: afeta a coleta dos itens. Isto depende do local de uso (quanto mais locais de uso, maior a dificuldade e o custo da coleta); intensidade (uso: frequente ou ocasional) e duração de uso (vida longa ou curta);

$\checkmark$ Características de deterioração: O ciclo de vida dos produtos é cada vez menor, apresentando diferentes tempos, processos e terminologias relacionadas a sua deterioração, entres elas: Deterioração intrínseca: quanto tempo dura o produto?; Reparabilidade: o produto pode ser facilmente reparado ou pode ser melhorado?; Homogeneidade da deterioração: todas as partes envelhecem igualmente, ou não?; Deterioração econômica: obsolescência programada, devido à entrada de novas versões do produto no mercado.

A abordagem da logística reversa possui uma relação sistêmica com a green supply chain management, fazendo parte desse conceito de gestão da cadeia de suprimentos. Nesse sentido, alguns autores têm se dedicado ao estudo dos desafios das empresas brasileiras, no que diz respeito à internalização dos pressupostos dessa abordagem em seus processos produtivos e, também, ao longo de suas cadeias de suprimentos.

Nos últimos anos, várias empresas recriaram seus processos produtivos de modo a incorporar a Logística Reversa. Segundo Stock e Mulki (2009), as empresas que caminham nessa direção estão antecipando as 
mudanças na legislação ambiental e adequando seus processos ao novo perfil do consumidor, propiciado pela revolução do marketing verde. Além disso, ao priorizar a reutilização e a reciclagem de produtos, reduzem-se o consumo de matéria-prima e a disposição final de resíduos.

Muitas empresas acreditam que os custos e a complexidade de se estabelecerem fluxos reversos não compensam o possível retorno financeiro (JAYARAMAN e LUO, 2007). Essa complexidade está associada à necessidade de se estabelecerem novas relações entre os diversos atores da cadeia produtiva, o que exige esforços de coordenação por parte das empresas. Algumas razões para o desinteresse em implantar sistemas de Logística Reversa, comentados por Braga e outros (2006) são:

$\checkmark$ Dificuldade das empresas em medir o impacto efetivo do retorno de produtos;

$\checkmark$ Fluxo reverso ser entendido como uma atividade de alto custo paralela às operações usuais da empresa.

\section{METODOLOGIA}

O presente artigo compreende uma pesquisa bibliográfica descritiva e exploratória, quantitativa e seguida de um estudo de caso desenvolvido através de um levantamento de dados á respeito da quantidade de embalagens vazias de agrotóxicos descartados mensalmente e sobre a destinação das mesmas.

A pesquisa trata-se de um levantamento teórico dos dados e informações, a pesquisa descritiva tem a finalidade de observar, registar e analisar os fenômenos sem interferência do pesquisador, já a pesquisa exploratória verifica se os dados levantados condizem com a realidade abordada e se os dados coletados realmente condizem com o estudo. A pesquisa quantitativa prioriza a frequência e intensidade do comportamento do indivíduo, por isso essas medidas são precisas e são uteis para decisões mais acertadas. O estudo de caso é uma estratégia para o desenvolvimento e precisão dos objetivos, pois acompanha in loco a compreensão dos dados levantados.

Além disso, foi aplicado questionário ao proprietário rural envolvido na questão em estudo, que possui propriedade rural localizada na Linha Porto Chalana, na cidade de Guatambu (SC). O questionário aplicado teve como propósito identificar o volume de embalagens vazias de agrotóxicos descartadas mensalmente e sobre a destinação final das mesmas.

Por não tratar-se de uma empresa constituída, não se tem registro algum a respeito da quantidade de embalagens vazias e tampouco sobre sua destinação final. Sendo assim, para realizarmos esse artigo, os autores realizaram uma entrevista com o proprietário da área rural, que serviu como campo de 
estudo para o artigo, onde forma extraídos os dados necessários para o desenvolvimento deste estudo, bem como para discutir a importância e os benefícios da logística reversa na destinação das embalagens vazias.

\subsection{DISCUSSÃO DOS RESULTADOS}

O campo de atuação desse artigo tratase de uma propriedade rural localizada na Linha Porto Chalana, na cidade de Guatambu (SC). Com uma área total de 125 hectares reservados para o plantio de milho, soja e trigo.

Com três colaboradores para manutenção da área e para o auxilio nas atividades diárias, a propriedade possui 15 hectares de reserva legal/APP (área de preservação permanente), 3 hectares de reflorestamento. $\mathrm{Na}$ propriedade existem $2.700 \mathrm{~m}^{2}$ de área construída e $7.000 \mathrm{~m}^{2}$ de açudes.
A propriedade em estudo já utiliza a logística reversa na destinação correta das embalagens vazias de agrotóxicos. Porém, não se tem uma mensuração dos custos com essa destinação, tampouco sobre o armazenamento temporário das mesmas, uma vez que todo o custo aplicado fica para a empresa fornecedora do produto.

Os agrotóxicos são adquiridos de um único fornecedor na cidade de Chapecó (SC), o que favorece uma destinação correta das embalagens vazias. Manter a parceria com empresas que praticam a sustentabilidade e responsabilidade ambiental é uma estratégia utilizada e um forte aliado na redução de custos e impactos socioambiental que o processo possa causar.

Os principais produtos plantados na propriedade são trigo, milho e a soja. Conforme mostra a tabela a seguir, é possível observar a extensão de área plantada entre os anos 2012 e 2014.

Tabela 1: Principais produtos plantados.

\begin{tabular}{|c|c|c|c|c|}
\hline Produto & 2012 & & & 2014 \\
\hline Soja & 870 ha & 900 ha & 900 ha & \\
\hline Milho & 193 ha & 273 ha & 300 ha & \\
\hline Trigo & 320 ha & 440 ha & 500 ha & \\
\hline
\end{tabular}

Fonte: Cooperativa Agroindustrial Alfa (2015)

Entre os agrotóxicos utilizados no processo de plantio que vai desde a dessecação da área até a colheita do produto, estão o fungicida e o inseticida. Também é usado o espelhante adesivo que tem como principal função o aumento da quantidade de principio ativo sobre a planta reduzindo a perda por evaporação e deriva. 
É possível observar a função que cada agrotóxico utilizado tem a plantação, bem como em quais etapas do processo eles são necessários, exemplificado na figura.

Figura 2: Agrotóxicos utilizados e sua função:

\begin{tabular}{|c|l|l|}
\hline AGROTÓXICO & \multicolumn{1}{|c|}{ FUNÇÃO } & \multicolumn{1}{|c|}{ PROCESSO } \\
\hline Fungicida & $\begin{array}{l}\text { Serve para eliminar fungos. Pode ser utilizado } \\
\text { com prevenção antes da existência de fungos } \\
\text { na plantação ou para combater um fungo } \\
\text { existente. }\end{array}$ & $\begin{array}{l}\text { - Limpa. } \\
\text { - Prevenção. }\end{array}$ \\
\hline Inseticida & $\begin{array}{l}\text { Usado para combater pragas que assolam as } \\
\text { plantações. }\end{array}$ & $\begin{array}{l}\text { - Dessecação. } \\
\text { - Limpa. } \\
\text { - Prevenção. }\end{array}$ \\
\hline Espalhante Adesivo & $\begin{array}{l}\text { Pode ser adicionado ao fungicida ou inseticida } \\
\text { dando maior eficácia nas aplicações, } \\
\text { aumentando seu princípio ativo sobre a planta. }\end{array}$ & $\begin{array}{l}\text { Prevenção (Combate a } \\
\text { fungos e insetos). }\end{array}$ \\
\hline
\end{tabular}

Fonte: Autores (2015).

Tanto no processo de dessecação como também no processo de limpa da área do plantio, são usadas quantidades consideráveis de inseticida e fungicida. Após o crescimento das plantas, há a necessidade de prevenção de pragas que possam aparecer exigindo a aplicação destes agrotóxicos em até três vezes durante o processo de crescimento da plantação, até estarem em ponto de colheita.
A tabela a seguir é possível identificar a quantidade de agrotóxicos utilizados por alqueire plantado, desde a dessecação da área de plantio, o limpa e as prevenções necessárias conforme a necessidade de cada produto bem como a quantidade total de agrotóxico necessário do início ao fim do processo.

Tabela 2: Quantidade de Agrotóxicos necessários por produto.

\begin{tabular}{|c|c|c|c|c|c|c|}
\hline \multirow[t]{2}{*}{ Produto } & \multirow{2}{*}{$\begin{array}{l}\text { Dessecação } \\
\text { (fung/ inset) }\end{array}$} & \multirow{2}{*}{$\begin{array}{l}\text { Limpa } \\
\text { (fung/ inset) }\end{array}$} & \multicolumn{3}{|c|}{ Prevenção } & \multirow[t]{2}{*}{ Total } \\
\hline & & & Fungicida & a Inseticida & Espalha & \\
\hline Soja & $5 \mathrm{~L} / \mathrm{ha}$ & $2,65 \mathrm{~L} / \mathrm{ha}$ & 1,2 L/ha & $0,9 \mathrm{~L} / \mathrm{ha}$ & 1,5 L/ha & $11,25 \mathrm{~L}$ \\
\hline Milho & $5 \mathrm{~L} / \mathrm{ha}$ & $7 \mathrm{~L} / \mathrm{ha}$ & - & - & - & $12 \mathrm{~L}$ \\
\hline Trigo & 4,5 L/ha & $0,4 \mathrm{~L} / \mathrm{ha}$ & $1 \mathrm{~L} / \mathrm{ha}$ & $0,21 \mathrm{~L} / \mathrm{ha}$ & 1,5 L/ha & 7,61 L \\
\hline
\end{tabular}

Fonte: Cooperativa Agroindustrial Alfa (2015). 
Levando em consideração a necessidade de aplicação de fungicida $\mathrm{e}$ inseticida durante o crescimento da planta, isso faz com que a quantidade de agrotóxicos utilizados seja expressiva.
A próxima tabela relata a quantidade de agrotóxicos utilizados pela propriedade rural referenciada no plantio de soja, milho e trigo, entre os anos de 2012 á 2014, bem como o total utilizado durante o ano.

Tabela 3: Quantidade de Agrotóxicos (litros) utilizado no período de 2012-2014 na propriedade pesquisada.

\begin{tabular}{lcrr}
\hline Lavoura & 2012 & \multicolumn{1}{c}{2013} & \multicolumn{1}{c}{2014} \\
\hline Soja & $9.787,50$ & $10.125,00$ & $10.125,00$ \\
Milho & $2.316,00$ & $3.276,00$ & $3.600,00$ \\
Trigo & $2.435,20$ & $3.348,40$ & $3.805,00$ \\
Total em Litros & $\mathbf{1 4 . 5 3 8 , 7 0}$ & $\mathbf{1 6 . 7 4 9 , 4 0}$ & $\mathbf{1 7 . 5 3 0 , 0 0}$ \\
\hline
\end{tabular}

Fonte: Cooperativa Agroindustrial Alfa (2015).

A diferença na quantidade de entender todo $\mathrm{o}$ processo do uso de agrotóxicos utilizada entre um ano e outro é agrotóxicos, desde a sua compra até a pequena, pois o processo em si é estável, o destinação das embalagens vazias. O processo que possibilita uma prospecção aproximada de compra e uso de agrotóxico praticado na dos custos necessários com a obtenção destes propriedade, bem como a prática da Logística produtos, no ano que segue.

Através de informações do Reversa no retorno das embalagens vazias de proprietário da área rural, foi possível agrotóxicos atendem a Resolução CONANA no 334 de 03 de abril de 2003. 
Figura 3: Fluxograma do processo praticado pelos agricultores.

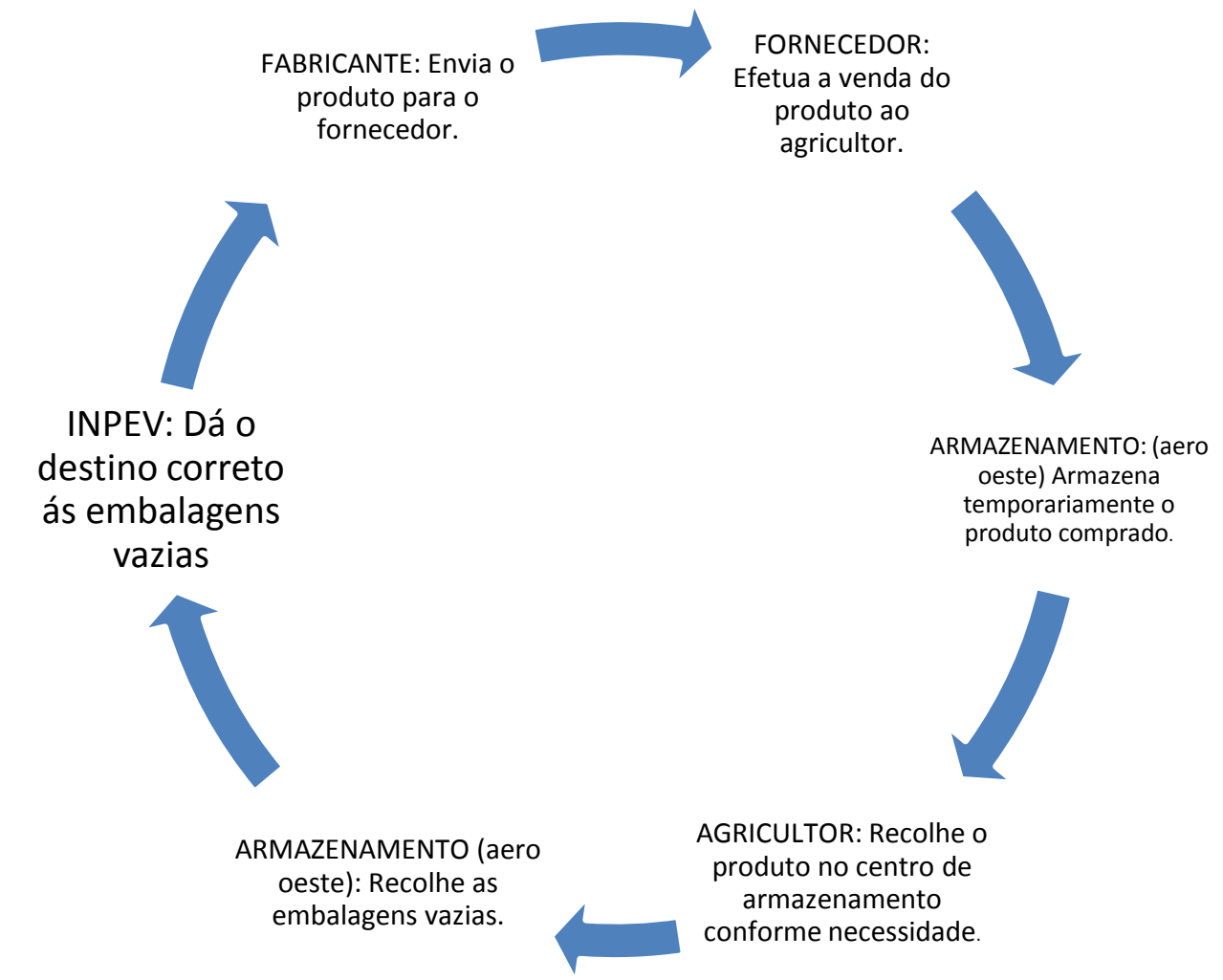

Fonte: Autores (2015).

Para garantir que todo o processo ainda a legislação ambiental vigente, todo o processo é feito somente por empresas licenciadas pelos órgãos ambientais. Sendo assim, o produtor rural em questão realiza a compra de agrotóxicos de um fornecedor exclusivo, que traz os produtos diretamente do fabricante. Sempre que o produtor efetua a compra, o fornecedor transporta todo o produto comprado até o Aera Oeste (associação das empresas revendedoras de agroquímicos de Chapecó e região), que armazena todo o agrotóxico e só disponibiliza ao proprietário quando houver a necessidade de uso, visando a prevenção de todo o impacto ambiental que possa causar, em caso de armazenamento inadequado.

Quando solicitado para uso, o fornecedor transporta o agrotóxico até a propriedade que fará uso dos produtos, somente na quantidade necessária para evitar que possíveis sobras do produto possam ser despejadas em locais inadequados contribuindo para a contaminação do solo e lençol freático.

Após o uso do produto, é realizada a tríplice lavagem, que consiste na preparação da embalagem vazia para uma possível reutilização, após avaliações do INPEV.

Após concluir esta etapa do processo, todas as embalagens têm seu fundo cortado, 
para evitar sua reutilização de forma inadequada, e armazenada temporariamente na propriedade rural, até ser coletada pela Aera Oeste que as mantém no centro de armazenamento por um período de aproximadamente seis meses, até juntar uma grande quantidade para transporte.

Ao chegar ao centro de armazenamento, toda embalagem tem sua tampa retirada, em seguida é prensada, amarradas em pequenos fardos e a cada seis meses, todas as embalagens vazias são devidamente tratado, carregado e encaminhado para á INPEV para destinação final. Fiscalizado pela CIDASC, FATMA e Ministério Público.

Através desta constatação, é possível visualizar um crescimento na quantidade de embalagens vazias enviadas á INPEV pela Aero Oeste entre os anos de 2001 a 2014. Conforme prevê a Lei Ambiental 9.974 de 2.000 , toda embalagem vazia de agrotóxico pode ser reutilizada apenas uma vez. Após seu reuso, ela só pode ser destinada na produção de outros produtos plásticos que não ofereçam riscos á saúde humana e animal.

Tabela 4: Embalagens vazias no período 2011-2014 recolhidas pela Aeraoeste.

\begin{tabular}{ll}
\hline Ano & Quantidade \\
\hline 2011 & 156 toneladas \\
2012 & 184 toneladas \\
2013 & 200 toneladas \\
2014 & 257 toneladas \\
\hline
\end{tabular}

Fonte: Autores (2015).

Segundo o fornecedor de defensivos agrícolas da propriedade rural pesquisada, estima-se que $90 \%$ das embalagens vazias são recolhidas. O restante são destinadas de forma inadequada ou reutilizadas incorretamente.

Todo produto vencido, é recolhido pela Aera Oeste que providencia seu envio ao fabricante para reprocessamento e destinação correta e toda a logística existente desde o inicio do processo, é de tal responsabilidade do fornecedor do produto, incentivando $\mathrm{o}$ consumidor a agir de forma sustentável tendo a logística reversa como uma estratégia eficiente no retorno de embalagens vazias de agrotóxicos.

\section{CONSIDERAÇÕES FINAIS}

Devido á complexidade exigida dos controles de venda e utilização de agrotóxicos, bem como o processo de destinação final das embalagens vazias, a utilização da logística empresarial é uma 
estratégia que garante com que as regulamentações ambientais do CONANA sejam cumpridas. A obrigatoriedade estendida aos fornecedores de agrotóxicos, no que diz respeito á coleta e destinação correta destas embalagens, faz com que seja adotada a logística reversa, incentivando aos proprietários de terras a cumprir com suas obrigações, realizando a tríplice lavagem e armazenando-as temporariamente até sua coleta, sem custo algum para o consumidor final.

Em meio ao aumento considerável do uso de agrotóxicos, percebeu-se que manter um controle eficiente sobre a destinação final dessas embalagens se tornou uma necessidade. Só no primeiro semestre de 2014, foram descartadas mais embalagens do que durante todo o ano de 2013. Isso mostra que o consumo de agrotóxicos está dobrando, e que a necessidade de acompanhamento da destinação final destas embalagens precisa ser aprimorada.

Observou-se no estudo que a propriedade rural atende a legislação ambiental vigente, realizando todos os processos de utilização e reciclagem das embalagens vazias de forma correta, realizando a tríplice lavagem, armazenando e disponibilizando-as ao fornecedor responsável para prensagem e destinação correta. Observou-se através da entrevista realizada, que o proprietário tem ciência da importância que a logística reversa tem na destinação correta das embalagens vazias bem como dos malefícios que o agrotóxico pode trazer á saúde humana e animal caso estas embalagens sejam reutilizadas de forma inadequada e nos impactos ambientais que podem causar caso não sejam destinadas de forma correta.

De modo geral, embora não houvesse registro dos dados necessários para o desenvolvimento deste artigo, a transparência dos processos de venda e controle de embalagens vazias do fornecedor de agrotóxico, possibilitou o levantamento de todas as informações necessárias, sendo possível mostrar os reais benefícios que a logística reversa traz ao meio ambiente e á vida humana, quando se procede de forma correta cumprindo as legislações ambientais vigentes.

\section{REFERÊNCIAS}

ALMEIDA, F. O bom negócio da sustentabilidade. Rio de Janeiro: Nova Fronteira, 2002.

BOWERSOX, D. J; CLOSS, D. J; HELFERICH, O. K. Logistical management: a systems integration of physical distribution, manufacturing, support and materials procurement. 3. ed. New York: Macmillan, 1986.

BRAGA JUNIOR, S.S; COSTA, P. R.; MERLO, E. M. Logística reversa como alternativa de ganho para o varejo: um estudo de caso em um supermercado de médio porte. Anais do IX Simpósio de Administração da Produção, Logística e Operações Internacionais: Simpoi 2006. São Paulo: FGV-EAESP, 2006. 
BRASIL. Casa Civil. Lei no 12.305 , de 2 de agosto de 2010. Disponível em:

http://www.planalto.gov.br/ccivil_03/_Ato20

07-2010/2010/Lei/L12305.htm. Acesso em 17

set 2015 .

DE BRITO, M. P.; DEKKER, R. Reverse logistics: a framework. Econometric Institute. Report EI 2002-38, Erasmus University Rotterdam, The Netherlands, 2002.

ELKINGTON, J. A terceira onda: grandes mudanças na direção das empresas. In: ELKINGTON, J. Canibais com garfo e faca. São Paulo: Makroom Books, 2001.

GONÇALVES-DIAS, S; TEODÓSIO, A. S. S. Estrutura da cadeia reversa: "caminhos" e "descaminhos" da embalagem PET. Produção, v. 16, n. 3, p. 429-441, 2006.

GUIDE JUNIOR, V. D. R; HARRISSON, T. P; VAN WASSENHOVE, L. N. The challenge of closed-loop supply chains. Interfaces, v. 33, n. 6, p. 3-6, 2003.

HART, S. L. \& MILSSTEIN, M. B. (2003). Creating sustainable value. Academy of Management Executive, 17(2), 56-67. doi: 10.5465/AME.2003.10025194

LEITE, P. R. Logística reversa: meio ambiente e competitividade. São Paulo: Prentice Hall, 2003.

JAYARAMAN, V; LUO, Y. Creating competitive advantages through new value creation: e reverse logistics perspective. Academy Management Perspective, v. 1, Issue 2, p. 56-73, 2007.

\section{LACERDA, L. Logística Reversa: Uma} visão sobre conceitos básicos e as práticas operacionais. Disponível em http://www.sargas.com.br/site/artigos_pdf/arti go_logistica_reversa_leonardo_lacerda.pdf. Acesso em 26 ago. 2015.

LEITE, P. R. Direcionadores (“drivers") estratégicos em programas de logística reversa no Brasil. In: SIMPÓSIO DE
ADMINISTRAÇÃO DA PRODUÇÃO, LOGÍSTICA E OPERAÇÕES

INTERNACIONAIS, 9, 2006, São Paulo. Anais. São Paulo: FGV-EAESP, 2006.

MOURA, Luiz A.A. Qualidade e gestão ambiental: Sugestões para implantação das Normas Técnicas ISSO 14.000 nas empresas $-3^{\circ}$ ed. São Paulo. Editora Juarez de Oliveira, 2011.

MUELLER, C. F. LR: meio ambiente e produtividade. Grupo de Estudos Logísticos da Universidade Federal de Santa Catarina, 2005.

NOVAES, A. G. Logística e gerenciamento da cadeia de distribuição. 2.ed. Rio de Janeiro: Campus, 2007.

PRAHINSKI, C.; KOCABASOGLU, C. Empirical research opportunities in reverse supply chains. Omega, v. 34, n. 6, p. 519-532, 2006.

REIS, Tatiana A. A sustentabilidade em empreendimentos da economia solidária: pluralidade e interconexão de dimensões. Dissertação (mestrado) — Universidade Federal da Bahia, Salvador, 2005.

RUBIO, S; MIRANDA, F. J; CHAMORRO, A; VALERO, V. Implementing a reverse logistics system: a case study. International Journal Procurement Management, v. 2, n. 4, p. 346-357, 2009.

\section{SACHS, I. Caminhos para o}

Desenvolvimento Sustentável. Rio de Janeiro: Garamond, 2002.

SACHS, I. Desenvolvimento includente sustentável. São Paulo: Garamod, 2004.

SAVITZ, Andrew. W. A Empresa

Sustentável. O verdadeiro sucesso é o lucro com responsabilidade social e ambiental $-4^{\circ}$ ed. Rio de Janeiro. Elsevier, 2007.

STOCK, J. R; MULKI, J. P. Product returns processing: an examination of practices of 
manufacturers, wholesalers, distributors and retailers. Journal of Business Logistics, v. 30, n. 1, p. 33-62, 2009.

TIBBEN-LEMBKE, R. S. Life after death: reverse logistics and the product life cycle. International Journal of Physical Distribution \& Logistics Management, v. 32, n. 3, p. 223244, 2002.

VEIGA, J. E.. "Sustentabilidade - A

Legitimação de um Novo Valor". Senac/SP. 160 páginas, 2010.

ZUCATTO, Luis Carlos; WELLE, Iara; SILVA, Tania Nunes da. Cadeia reversa do óleo de cozinha: coordenação, estrutura e aspectos relacionais. Rev. adm. empresa., São Paulo , v. 53, n. 5, p. 442-453, Oct. 2013 